\title{
REVIEW
}

\section{Pathways in pulmonary arterial hypertension: the future is here}

\author{
Olivier Sitbon* and Nicholas W. Morrell ${ }^{\#}$
}

ABSTRACT: It is well established that the endothelin, nitric oxide and prostacyclin pathways play an important role in the development of pulmonary arterial hypertension (PAH). Indeed, the therapeutic options currently available for the management of PAH all act on one of these mechanistic pathways.

However, this is an exciting time for both clinicians and scientists, as increased understanding of the mechanisms involved in the pathogenesis and progression of PAH has resulted in the development of a number of novel therapeutic options.

This article highlights how the introduction of new compounds such as macitentan, riociguat and selexipag, which act on the endothelin, nitric oxide and prostacyclin pathways, respectively, have the potential to further improve the prognosis for patients with PAH.

KEYWORDS: Endothelin, nitric oxide, prostacyclin, pulmonary arterial hypertension, survival

$\mathrm{P}$ ulmonary arterial hypertension (PAH) is a disease often considered to be driven by vasoconstriction. However, one cannot overlook the associated, profound remodelling of the vascular wall that mainly contributes to the pathogenesis of PAH. New medicines should seek to ameliorate the intimal fibrosis, endothelial cell proliferation, medial thickening and smooth muscle cell hypertrophy and hyperplasia seen in the pulmonary vasculature of patients with $\mathrm{PAH}$ [1]. Major therapeutic advances have been made in the past $20 \mathrm{yrs}$, with the introduction of novel compounds that target the three key pathways involved in the development and progression of $\mathrm{PAH}$, namely: the endothelin (ET), nitric oxide (NO) and prostacyclin $\left(\mathrm{PGI}_{2}\right.$ ) pathways (fig. 1) [2]. Research is ongoing, and a new wave of medicines, with more potent antihypertensive and antiproliferative effects, are expected to be launched in the near future.

\section{THE ET PATHWAY}

It is well established that ET-1 is a key mediator of $\mathrm{PAH}$, driving pathological changes in the lung that lead to pulmonary vascular remodelling [35]. The effects of ET-1 are mediated via two ET receptor subtypes, ETA and ETB, to which ET-1 binds with high affinity $[6,7]$. ETA receptors are found in smooth muscle cells while ETB receptors are located in both endothelial cells and smooth muscle cells. ET-1, released from the endothelium, acts primarily on the underlying smooth muscle In addition, ET-1 acts on fibroblasts to induce contraction, proliferation and fibrosis, and on the endothelium itself to cause proliferation, vasodilation (via $\mathrm{NO}$ and $\mathrm{PGI}_{2}$ ) and vasoconstriction (via thromboxane $\mathrm{A}_{2}$ ). All three of these ET-driven processes play an important role in lung vascular and structural remodelling (fig. 2) [8].

A greater understanding of the ET system has elucidated a role for autocrine/paracrine signalling in the ET system and PAH pathway. The evidence to support this hypothesis is reinforced by a number of observations. For instance, cleavage of big ET-1 to form mature ET-1 is known to occur in situ $[7,9,10]$, and circulating plasma levels of ET-1 are below the pharmacological threshold levels required to elicit vasoconstriction. This is suggestive of a local site of action [6]. Additional support for the importance of autocrine/paracrine signalling includes the polarised secretion of ET-1, whereby $80 \%$ of the ET-1 produced by the endothelial cells is released basolaterally towards the vessel wall, and hence the tissue, while only $20 \%$ is released into the bloodstream [11]. Furthermore, DAVIE et al. [12] reported an increased number and density of ET receptors in the small pulmonary arteries of patients with idiopathic $\mathrm{PAH}$ and PAH associated with congenital heart disease. Not only does there seem to be a high concentration of ET receptors, there also seems to cells to cause vasoconstriction and proliferation.

\section{AFFILIATIONS}

*Université Paris-Sud, Hôpital de Bicêtre, Le Kremlin-Bicêtre, France. ${ }^{\#}$ Dept of Medicine, Addenbrooke's Hospital, University of Cambridge, Cambridge, UK.

CORRESPONDENCE

N.W. Morrell

Dept of Medicine

Addenbrooke's Hospital

University of Cambridge

Hills Road

Cambridge

CB2 OQQ

UK

E-mail: nwm23@medschl.cam.ac.uk

Received:

Aug 232012

Accepted after revision:

Sept 212012

\section{PROVENANCE}

Publication of this peer-reviewed article was supported by Actelion Pharmaceuticals Ltd, Switzerland (principal sponsor, European Respiratory Review issue 126). 
a)

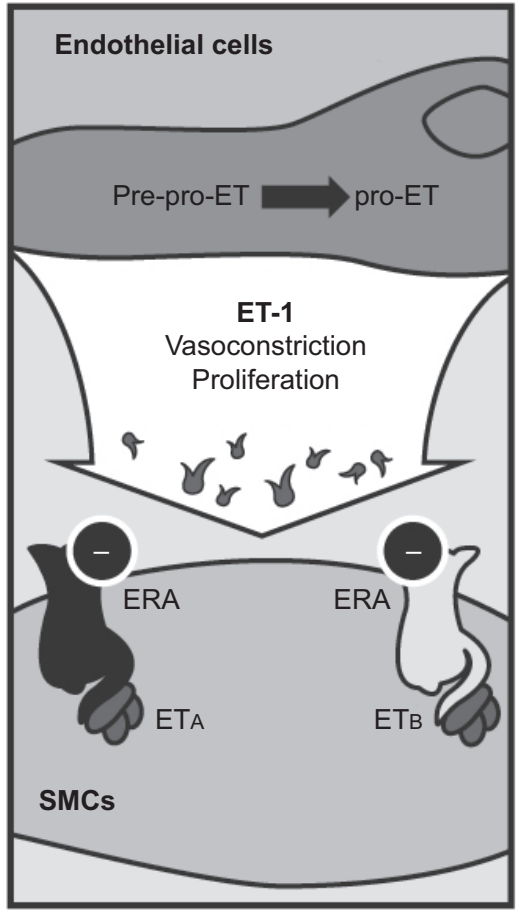

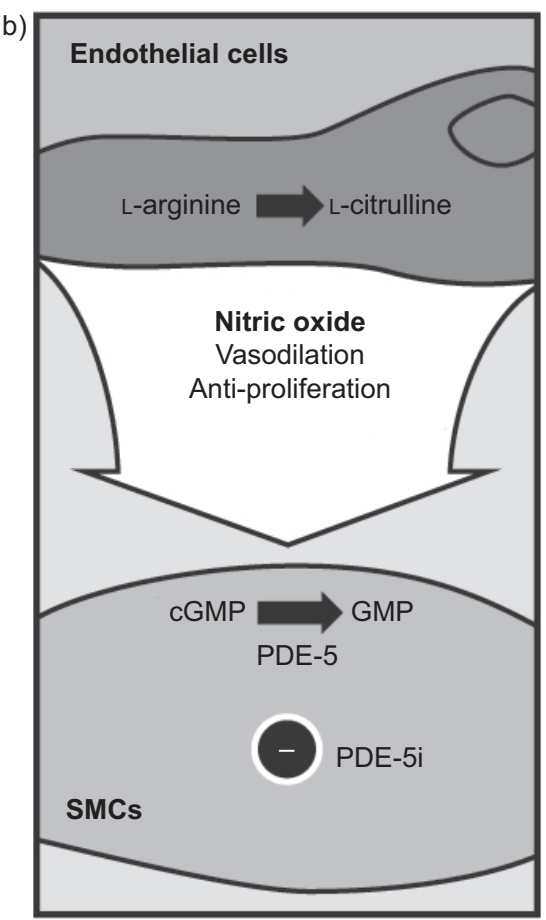

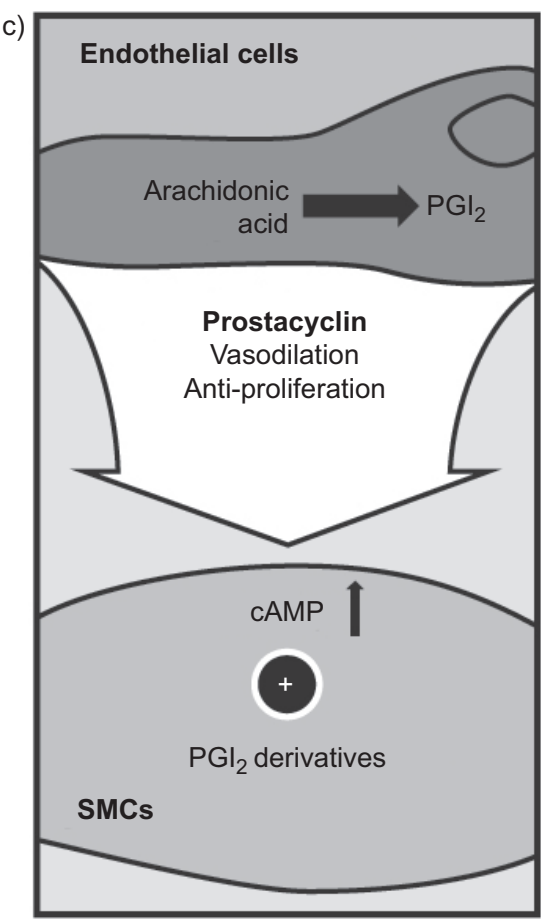

FIGURE 1. Key pathways involved in the pathogenesis of pulmonary arterial hypertension: a) endothelin (ET) pathway; b) nitric oxide pathway; and c) prostacyclin (PGI 2 ) pathway. ERA: ET receptor antagonist; ETA/ETB: ET receptor subtypes A and B; SMCs: smooth muscle cells; cGMP: cyclic guanosine monophosphate (GMP); PDE-5: phosphodiesterase type-5; PDE-5i: PDE-5 inhibitor; cAMP: cyclic adenosine monophosphate. Reproduced from [2] with permission from the publisher.

be continuous occupancy of these receptors by their agonist $[13,14]$. These findings have prompted the development of new endothelin receptor antagonists (ERAs), such as macitentan, which demonstrate enhanced tissue penetration, improved receptor binding/affinity and superior efficacy compared with the currently available drugs (bosentan and ambrisentan).

Macitentan is a novel dual ERA currently in phase III of clinical development. As mentioned previously, the majority of ETinduced effects occur deep within the tissues so it is important that any new, potential antagonist of ET can readily penetrate the lipid bilayer. Results from in vitro studies demonstrated that macitentan has a higher ionisation dissociation constant $(\mathrm{pKa}=6.2)$ than bosentan $(\mathrm{pKa}=5.1)$ or ambrisentan $(\mathrm{pKa}=3.5)$ [15]. At a pKa of $6.2,6 \%$ of macitentan is non-ionised at physiological $\mathrm{pH}$, which, in turn, facilitates passage across the lipid bilayer. This means that macitentan has a greater affinity for the lipid phase compared with other ERAs and, accordingly, has greater tissue-targeting potential. This supposition is supported by the results from an experimental rat model of pulmonary fibrosis. In this study, micro-autoradiographs indicating the localisation of each drug demonstrated greater tissue penetration with macitentan compared with bosentan [16].

Studies in animal models suggest that macitentan has improved efficacy compared with other ERAs. Macitentan was shown to be more efficacious than bosentan in reducing the development of pulmonary fibrosis and right ventricular hypertrophy in the rat model of pulmonary fibrosis associated with PAH [16]. In addition, a study using the deoxycorticosterone acetone-salt rat model of hypertension investigated the effect of acute oral macitentan versus bosentan administration on mean arterial pressure. Macitentan was shown to be 10-fold more potent than bosentan and displayed a two-fold longer duration of action [15, 17]. Pre-clinical data also suggest beneficial long-term effects of macitentan; macitentan $\left(30 \mathrm{mg} \cdot \mathrm{kg}^{-1} \cdot \mathrm{day}^{-1}\right)$ elicited a significant improvement in survival in a monocrotaline (MCT) rat model of PAH when compared with untreated controls (fig. 3) [15]. Survival at 42 days in rats was $83 \%$ with macitentan and $50 \%$ with the vehicle control $(\mathrm{p}=0.002)$, which represents a $66 \%$ reduction in mortality.

Safety and tolerability with ERAs is an important consideration, especially as it is not known whether patients treated with these agents may experience an increased incidence of hepatic side-effects [8]. There are several known mechanisms for this class effect, including inhibition of the bile salt export pump (BSEP). The BSEP is the major transport protein for bile salt export and its inhibition can lead to elevated liver enzymes. Bosentan inhibits BSEP, resulting in disruption of bile salt homeostasis, which can cause hepatic cholestasis and liver damage [18]. Unlike bosentan, in vivo data demonstrate that neither macitentan nor its active metabolite inhibit BSEP to a clinically relevant extent [17]. In contrast to bosentan, macitentan is given at a significantly lower dose $(10 \mathrm{mg}$ versus $125 \mathrm{mg}$ b.i.d.) and is mainly excreted into urine. Furthermore, in the Macitentan Use in an Idiopathic Pulmonary Fibrosis Clinical (MUSIC) study (a phase II trial of macitentan in idiopathic pulmonary fibrosis), the incidence of liver enzyme elevations with macitentan was similar to placebo $(3.4 \%$ and $5.1 \%$, respectively) [19]. Based on these experiments, pivotal toxicology data and clinical trial results, it is expected that macitentan and its active metabolite are less likely to cause elevations in liver enzymes than bosentan. Pharmacokinetic 


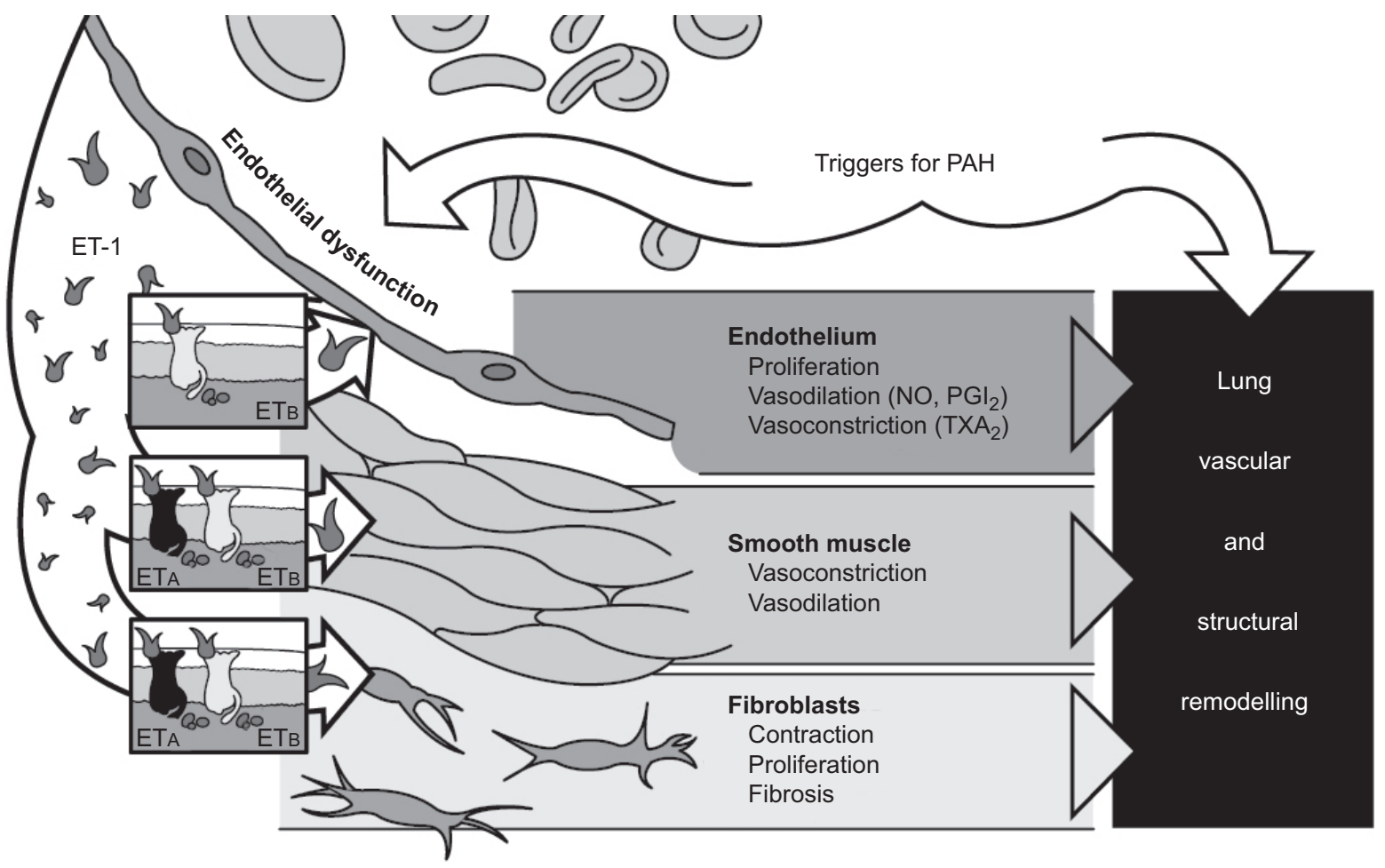

FIGURE 2. Endothelin (ET)-1 plays an important role in vascular remodelling. PAH: pulmonary arterial hypertension; ETA/ETB: ET receptor subtypes A and B; NO: nitric oxide; $\mathrm{PGl}_{2}$ : prostacyclin; $\mathrm{TXA}_{2}$ : thromboxane $\mathrm{A}_{2}$.

data from phase I studies support a once-daily dosing regimen for macitentan and demonstrate that it can be taken irrespective of food intake and without drug-drug interactions with warfarin, sildenafil, ketoconazole or cyclosporine [20, 21].

The results from the pre-clinical programme and from phase I and II studies suggest that macitentan is efficacious and well tolerated [22]. The recently completed phase III Study with an Endothelin Receptor Antagonist in Pulmonary Arterial Hypertension to Improve Clinical Outcome (SERAPHIN) study (Clinicaltrials.gov NCT00660179) was undertaken in 39 countries and randomised 742 patients with symptomatic PAH. SERAPHIN was a double-blind, randomised, placebo-controlled, event-driven study in which patients were randomised 1:1:1 to receive either $3 \mathrm{mg}$ or $10 \mathrm{mg}$ macitentan or placebo once daily, in addition to their current (if any) PAH medication (although patients receiving other ERAs were excluded). Historically, PAH trials have been short term (typically 12 16 weeks) and the primary end-points have focused on symptomatic or functional end-points such as the 6-min walk distance (6MWD). In contrast, SERAPHIN was an event-driven study whose primary end-point is time to first morbidity or mortality event. This was the largest, prospective-controlled study in PAH to date and will provide much needed data on the long-term treatment of patients with $\mathrm{PAH}$.

\section{THE NO PATHWAY}

$\mathrm{PAH}$ is associated with impaired production of the endotheliumderived vasodilator, $\mathrm{NO}$ [23]. In healthy individuals, $\mathrm{NO}$ acts on smooth muscle cells to induce vasodilation and inhibit proliferation by increasing production of the secondary messenger cyclic guanosine monophosphate (cGMP) via activation of soluble guanylate cyclase [24, 25]. Treatment of pulmonary hypertension $(\mathrm{PH})$ with NO-releasing agents such as nitrates has failed to produce beneficial long-term effects as, in most cases, negligible pulmonary vasodilation was counterbalanced by significant peripheral reduction in vascular resistance and reflex tachycardia [26], both of which are poorly tolerated by patients with severe $\mathrm{PH}$. An alternative therapeutic strategy targets downstream components of the NO signalling pathway by inhibiting phosphodiesterase type-5 (PDE-5), the enzyme that catalyses the conversion of cGMP to GMP [27]. Sildenafil and tadalafil have been the lead substances in this group of agents, showing both acute and long-term beneficial effects in patients with PAH [2830]. However, PDE-5 inhibition is not effective in all patients with PH [31]; therefore, the full therapeutic potential of inducing the NO signalling pathway remains to be exploited.

Riociguat offers a new mode of action for the treatment of PAH by acting directly on soluble guanylate cyclase, stimulating the enzyme and increasing sensitivity to low levels of $\mathrm{NO}$ [32]. Phase II proof-of-concept studies in PAH and chronic thromboembolic PH (CTEPH) have demonstrated that riociguat was generally well tolerated and improved exercise capacity, symptoms and pulmonary haemodynamics in patients with PAH or CTEPH $[32,33]$. Phase III randomised controlled trials are currently underway. The Pulmonary Arterial Hypertension sGC-Stimulator Trial (PATENT) is a randomised, placebo-controlled trial that investigates the efficacy and safety of riociguat in patients with PAH (Clinicaltrials.gov NCT00810693). Patients were treated with riociguat or placebo for 12 weeks. The primary end-point in PATENT is $6 \mathrm{MWD}$ at 16 weeks. PATENT-2 is the open-label 


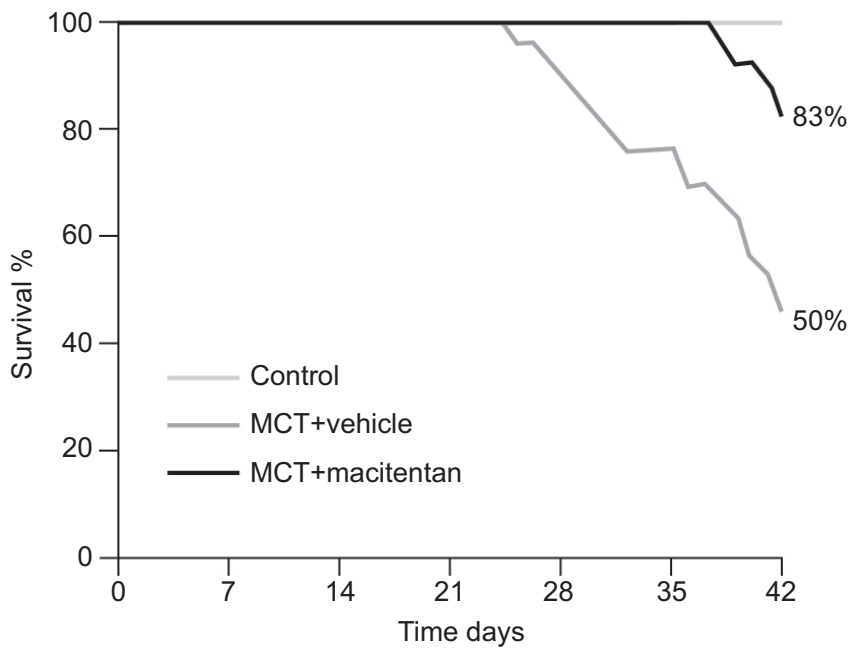

FIGURE 3. Effect of macitentan on survival in a monocrotaline (MCT) rat model of pulmonary hypertension. $p=0.002$. Reproduced from [15] with permission from the publisher

extension study in which patients are invited to participate. The Chronic Thromboembolic Pulmonary Hypertension sGCStimulator Trial (CHEST) is a randomised, placebo-controlled trial looking at the efficacy and safety of riociguat versus placebo in CTEPH patients (Clinicaltrials.gov NCT00855465). Again, the primary end-point is the change in 6MWD. On completion of CHEST-1, patients are invited to enter the open-label extension trial, CHEST-2. The results of the riociguat phase III studies, CHEST-1 and PATENT-1, are expected in mid-to-late 2012.

\section{THE $\mathrm{PGI}_{2}$ PATHWAY}

The $\mathrm{PGI}_{2}$ pathway has an established role in the pathogenesis of $\mathrm{PAH}[2,34]$. This pathway is activated when $\mathrm{PGI}_{2}$ stimulates the IP receptor, leading to increased cyclic adenosine monophosphate and resulting in vasodilatory and antiproliferative effects [34]. PAH patients have reduced levels of endogenous $\mathrm{PGI}_{2}$ and reduced expression of $\mathrm{PGI}_{2}$ synthase in the lung $[35,36]$. Several PAH-specific therapies have been developed that target the $\mathrm{PGI}_{2}$ pathway [34]. However, there are significant limitations associated with currently approved therapies, including inconvenient modes of administration (by continuous intravenous or subcutaneous injection, or inhalation), short half-life and nonspecific receptor interactions [37, 38]. Currently, there are no licensed oral $\mathrm{PGI}_{2}$ or $\mathrm{PGI}_{2}$ analogues available in Europe or the USA. Parenteral prostanoids are available but their uptake has been poor, presumably because of difficulties with administration. This was clearly illustrated in the Registry to Evaluate Early and Long-Term PAH disease (REVEAL) study, which demonstrated that $\sim 40 \%$ of patients who died from PAH had not received prostanoid therapy at the time of death [39].

Clearly, an oral $\mathrm{PGI}_{2}$ or $\mathrm{PGI}_{2}$ analogue would be a welcome addition to the portfolio of drugs used in the management of patients with $\mathrm{PAH}$. Several oral therapies that target the $\mathrm{PGI}_{2}$ pathway are in clinical development. One of these, oral treprostinil, has been studied in three phase III, multinational, placebo-controlled trials; as monotherapy in FREEDOM-M and in combination with background therapy in FREEDOM-C and FREEDOM-C2 (Clinicaltrials.gov NCT00325403, NCT00325442 and NCT00887978, respectively) [40]. The primary end-point for all three trials was change in 6MWD at 12 weeks in FREEDOM-M and at 16 weeks for FREEDOM-M and FREEDOM-C/C2. In FREEDOM-M, treprostinil improved 6MWD in comparison with placebo (treatment effect of $+23 \mathrm{~m} ; \mathrm{p}=0.0125$ ). Among the secondary end-points, 6MWD at week 8 and combined 6MWD and Borg dyspnoea score were significantly improved by treprostinil. However, treprostinil did not significantly affect World Health Organization (WHO) functional class or time to clinical worsening. In FREEDOM-C and FREEDOM-C2, preliminary analyses have shown that the primary end-points were not met [41, 42]. Another molecule that was under clinical investigation was beraprost. Beraprost is an orally active $\mathrm{PGI}_{2}$ analogue developed for the treatment of PAH. However, it has a short half-life $(\sim 1 \mathrm{~h})$ [43] and only modest, transient clinical benefits [44]. A recent phase II trial with a sustained-release formulation of beraprost failed to meet its primary end-point and, as a result, plans to commence a phase III trial with beraprost (sustained-release formulation) have been suspended (Clinicaltrials.gov NCT00989963) [45-47].

On a more optimistic note, there are promising clinical trial results with the first-in-class non-prostanoid IP receptor agonist selexipag $[34,38]$. Selexipag is a potent, orally active molecule which is rapidly hydrolysed to an active metabolite, ACT333679. Both selexipag and its metabolite are highly selective for the IP receptor compared with other prostanoid receptors such as EP, DP, FP and TP $[2,34-36,38]$. This selectivity for the IP receptor offers the potential for improved tolerability with selexipag, as side-effects (e.g. nausea and vomiting) that might result from activation of the other prostanoid receptors may be minimised [48]. In addition, the selexipag metabolite has a halflife of $7.9 \mathrm{~h}$, thus permitting oral dosing twice daily [38].

Selexipag has been studied in a randomised, double-blind, placebo-controlled, phase II, proof-of-concept trial in 43 patients with PAH [49]. Approximately one-third of patients were receiving both an ERA and sildenafil as background therapy. Selexipag was up-titrated in $200 \mu \mathrm{g}$ b.i.d. increments to the maximum tolerated dose. More than $60 \%$ of patients were on a final selexipag dose of $600-800 \mu \mathrm{g}$ b.i.d. Throughout the study selexipag was well tolerated with the majority of adverse events being mild or moderate in severity. Selexipag significantly lowered pulmonary vascular resistance (PVR) in comparison with placebo at week 17 (treatment effect of $-30.3 \% ; p=0.0045$ ). In addition, there was an improvement in 6MWD (treatment effect of $+24.7 \mathrm{~m}$ ), although this did not reach statistical significance. Compared with placebo, selexipag treatment was associated with a significant increase in cardiac index (treatment effect of $\left.+0.5 \mathrm{~L} \cdot \mathrm{min}^{-1} \cdot \mathrm{m}^{-2} ; \mathrm{p}=0.01\right)$. Further investigation of selexipag is ongoing in the double-blind, randomised, placebocontrolled, phase III GRIPHON (Prostaglandin $\left(\mathrm{PGI}_{2}\right)$ Receptor Agonist in Pulmonary Arterial Hypertension) study. GRIPHON has a clinically relevant and highly robust primary end-point of time to first morbidity/mortality event and will provide vital information on the long-term effects of selexipag in patients with PAH (Clinicaltrials.gov NCT01106014).

\section{ADVANCES IN OTHER PATHWAYS Tyrosine kinase inhibitors}

Platelet-derived growth factor (PDGF) is a serum growth factor for several cell types, including vascular smooth muscle cells 
and fibroblasts [50]. As a potent mitogen, PDGF exerts its effects via two receptor tyrosine kinases: PDGFR- $\alpha$ and PDGFR- $\beta$ [51]. Evidence suggesting a role for PDGF in the pathophysiology of PAH implies that inhibition of the PDGF pathway may represent a therapeutic target for the development of novel pharmacological strategies in PAH [52].

Imatinib is a tyrosine kinase inhibitor that was initially designed to treat chronic myelogenous leukaemia [53]. Imatinib can inhibit vascular smooth muscle cell proliferation and migration and, therefore, may suppress PDGF-induced vascular remodelling $[50,51]$. In support of this, imatinib has been shown to reverse pulmonary arterial smooth muscle cell proliferation and neointima formation in rats and mice [52]. Moreover, in rats with MCT-induced $\mathrm{PH}$, imatinib administered daily over 2 weeks resulted in 100\% survival compared with only $50 \%$ in sham-treated rats. In humans, several case reports have shown promising results for imatinib as a treatment for PAH [54-56]. However, one must caution that some of these patients had severe PAH and had exhausted all of the existing, traditional treatment options $[54,55]$.

The effects of imatinib in $\mathrm{PAH}$ were investigated in a randomised, double-blind, placebo-controlled phase II study [57]. 59 patients who remained in WHO functional class II-IV following $>3$ months of $\mathrm{PAH}$-specific therapy (including $\mathrm{PGI}_{2}$ analogues, ERAs or PDE-5 inhibitors) received treatment with oral imatinib (target dose $400 \mathrm{mg} \cdot \mathrm{day}^{-1}$ ) or placebo. After 24 weeks, the study failed to meet its primary efficacy endpoint of improvement in 6MWD. However, some secondary end-points, including PVR, were improved. A post hoc analysis, which stratified patients according to baseline median PVR, demonstrated improvements in 6MWD and haemodynamics in those patients treated with imatinib who had a baseline PVR $\geqslant 1,000 \mathrm{dyn} \cdot \mathrm{s} \cdot \mathrm{cm}^{-5}$. Although caution is warranted in interpreting the results of unplanned post hoc analyses, it is proposed that disease severity needs to reach a certain threshold for imatinib to be effective.

On the basis of the phase II data, the 24-week, double-blind, phase III Imatinib in Pulmonary Arterial Hypertension, a Randomized Efficacy Study (IMPRES) was initiated [58]. The aim of this study was to evaluate imatinib as an add-on therapy for the treatment of severe PAH. The IMPRES study included 202 patients with elevated PVR $\left(\geqslant 800 \mathrm{dyn} \cdot \mathrm{s} \cdot \mathrm{cm}^{-5}\right)$, despite treatment with at least two other PAH-specific medications. The results of the study demonstrated a significant improvement in 6MWD with imatinib versus placebo. Although significant improvements were shown for the secondary end-points of cardiac output, PVR and N-terminal pro-brain natriuretic peptide levels, this was not the case for the time to clinical worsening. There was also no significant change in WHO functional class, CAMPHOR (Cambridge Pulmonary Hypertension Outcome Review) quality of life score or Borg dyspnoea score. The overall incidence of adverse events was similar for imatinib and placebo. However, discontinuations due to serious adverse events were more frequent with imatinib. The serious adverse events included oedema, anaemia and subdural haematoma. The IMPRES extension study is currently underway to evaluate the long-term safety, tolerability and efficacy of imatinib in patients with severe PAH (Clinicaltrials.gov NCT01117987).
Tyrosine kinase inhibitors may represent a promising class of compounds for the future treatment of PAH. However, there are still a number of issues, such as the safety and tolerability profile, which need to be addressed. However, an important consideration is that currently imatinib cannot be used outside of clinical trials. In addition, not all tyrosine kinase inhibitors have the same intracellular target. It may be that molecules such as dasatinib, which may actually induce severe $\mathrm{PH}$ in patients with chronic myelogenous leukaemia, may target different receptor tyrosine kinases than a compound such as imatinib that appears to show benefit in PAH [59]. A clearer understanding of the tyrosine kinase pathway and receptors will be key to the future development of effective therapeutic agents in this class.

\section{Terguride}

Terguride is an oral, potent antagonist of serotonin (5-HT2A and 5-HT2B) receptors. Serotonin is a signalling molecule with many functions in the body. In blood vessels it stimulates proliferation of smooth muscle cells and constriction of the vessel wall which can induce PAH. Terguride binds to the 5HT2A and 5-HT2B receptors and inhibits the actions of serotonin on the vasculature, thereby attenuating the development of PAH. In 2008, terguride was granted orphan drug status for the treatment of PAH. Recent results from a double-blind, randomised, phase IIa study showed no overall significant effect of terguride compared with placebo on PVR or secondary endpoints, and the rate of severe and serious adverse events was higher with terguride. However, improvements in PVR among subjects already on PAH therapy with ERAs warrant further investigation [60].

\section{SUMMARY AND CONCLUSIONS}

This is an exciting time for clinicians and scientists involved in $\mathrm{PAH}$ research as several promising therapeutic options are in development for the treatment of this disease. Major advances have been made, with the introduction of novel compounds, such as macitentan, riociguat and selexipag, which target the three key pathways (ET, $\mathrm{NO}$ and $\mathrm{PGI}_{2}$, respectively) involved in the pathogenesis and progression of $\mathrm{PH}$. A number of important clinical trials in PAH are underway, the results of which are eagerly anticipated. The landmark SERAPHIN study, with the novel dual ERA macitentan, will provide much-needed information on the long-term effects of therapy on mortality and morbidity outcomes for patients with PAH. The GRIPHON study, with the IP receptor agonist selexipag, will give insight into the sustained effect of oral $\mathrm{PGI}_{2}$ agonists on long-term disease progression and it is hoped that PATENT-1 and CHEST-1 will elucidate the putative, therapeutic role of the soluble guanylate cyclase activator, riociguat, in patients with $\mathrm{PH}$. Clearly, with so much effort and activity in this field, it is hoped that, in the not too distant future, new treatment(s) will be available that will improve the prognosis for patients with PAH.

\section{STATEMENT OF INTEREST}

O. Sitbon has relationships with drug companies including Actelion, Bayer HealthCare, GSK, Eli Lilly, Pfizer and United Therapeutics. In addition to being an investigator in trials involving these companies, relationships include consultancy service and membership of scientific advisory boards. N.W. Morrell has received honoraria from Actelion for speaking at educational meetings. 


\section{ACKNOWLEDGEMENTS}

We received editorial assistance from L. Quine (Elements Communications Ltd, Westerham, UK) supported by Actelion Pharmaceuticals Ltd (Allschwil, Switzerland).

\section{REFERENCES}

1 Galiè N, Palazzini M, Manes A. Pulmonary arterial hypertension: from the kingdom of the near-dead to multiple clinical trial metaanalyses. Eur Heart J 2010; 31: 2080-2086.

2 Humbert M, Sitbon O, Simonneau G. Treatment of pulmonary arterial hypertension. N Engl J Med 2004; 351: 1425-1436.

3 Dupuis J. Endothelin: setting the scene in PAH. Eur Respir Rev 2007; 16: 3-7.

4 Galiè N, Manes A, Branzi A, et al. The new clinical trials on pharmacologic treatment in pulmonary arterial hypertension. Eur J Clin Investig 1996; 26: A48.

5 Giaid A, Yanagisawa M, Langleben D, et al. Expression of endothelin-1 in the lungs of patients with pulmonary hypertension. N Engl J Med 1993; 328: 1732-1739.

6 Galié N, Manes A, Branzi A. The endothelin system in pulmonary arterial hypertension. Cardiovasc Res 2004; 61: 227-237.

7 Iglarz M, Clozel M. At the heart of tissue: endothelin system and end-organ damage. Clin Sci (Lond) 2010; 119: 453-463.

8 Dupuis J, Hoeper MM. Endothelin receptor antagonists in pulmonary arterial hypertension. Eur J Respir 2008; 31: 407-415.

9 Teerlink JR, Carteaux JP, Sprecher U, et al. Role of endogenous endothelin in normal hemodynamic status of anesthetized dogs. Am J Physiol 1995; 268: H432-H440.

10 Haynes WG, Webb DJ. Contribution of endogenous generation of endothelin-1 to basal vascular tone. Lancet 1994; 344: 852-854.

11 Wagner OF, Christ G, Wojta J, et al. Polar secretion of endothelin-1 by cultured endothelial cells. J Biol Chem 1992; 267: 16066-16068.

12 Davie N, Haleen SJ, Upton PD, et al. ET(A) and ET(B) receptors modulate the proliferation of human pulmonary artery smooth muscle cells. Am J Respir Crit Care Med 2002; 165: 398-405.

13 Frelin C, Guedin D. Why are circulating concentrations of endothelin-1 so low? Cardiovasc Res 1994; 28: 1613-1622.

14 Desmarets J, Gresser O, Guedin D, et al. Interaction of endothelin-1 with cloned bovine ETA receptors: biochemical parameters and functional consequences. Biochemistry 1996; 35: 14868-14875.

15 Iglarz M, Binkert C, Morrison K, et al. Pharmacology of macitentan, an orally active tissue-targeting dual endothelin receptor antagonist. J Pharmacol Exp Ther 2008; 327: 736-745.

16 Iglarz M, Landskroner K, Rey M, et al. Optimization of tissue targeting properties of macitentan, a new dual endothelin receptor antagonist, improves its efficacy in a rat model of pulmonary fibrosis associated with pulmonary arterial hypertension. Am J Respir Crit Care Med 2011; 183: A6445.

17 Raja SG. Macitentan, a tissue-targeting endothelin receptor antagonist for the potential oral treatment of pulmonary arterial hypertension and idiopathic pulmonary fibrosis. Curr Opin Investig Drugs 2010; 11: 1066-1073.

18 Fattinger K, Funk C, Pantze M, et al. The endothelin antagonist bosentan inhibits the canalicular bile salt export pump: a potential mechanism for hepatic adverse reactions. Clin Pharmacol Ther 2001; 69: 223-231.

19 Raghu G, Million-Rousseau R, Morganti A, et al. Efficacy and safety of macitentan in idiopathic pulmonary fibrosis: results of a prospective, randomized, double-blind, placebo-controlled trial. Am J Respir Crit Care Med 2012; 185: A3631.

20 Bruderer S, Aänismaa P, Homery MC, et al. Effect of cyclosporine and rifampin on the pharmacokinetics of macitentan, a tissuetargeting dual endothelin receptor antagonist. AAPS J 2011; 14: 68-78.
21 Sidharta PN, Atsmon J, Dingemanse J. Investigation of the effect of ketoconazole on the pharmacokinetics of macitentan in healthy male subjects. Br J Clin Pharmacol 2010; 70: 730-731.

22 Sidharta PN, van Giersbergen PL, Halabi A, et al. Macitentan: entry-into-humans study with a new endothelin receptor antagonist. Eur J Clin Pharmacol 2011; 67: 977-984.

23 McLaughlin VV, McGoon MD. Pulmonary arterial hypertension. Circulation 2006; 114: 1417-1431.

24 Ignarro LJ, Buga GM, Wood KS, et al. Endothelium-derived relaxing factor produced and released from artery and vein is nitric oxide. Proc Natl Acad Sci USA 1987; 84: 9265-9269.

25 Arnold WP, Mittal CK, Katsuki S, et al. Nitric oxide activates guanylate cyclase and increases guanosine 3':5'-cyclic monophosphate levels in various tissue preparations. Proc Natl Acad Sci USA 1977; 74: 3203-3207.

26 Atz AM, Adatia I, Wessel DL. Rebound pulmonary hypertension after inhalation of nitric oxide. Ann Thorac Surg 1996; 62: 1759-1764.

27 Ghofrani HA, Osterloh IH, Grimminger F. Sildenafil: from angina to erectile dysfunction to pulmonary hypertension and beyond. Nat Rev Drug Discov 2006; 5: 689-702.

28 Ghofrani HA, Wiedemann R, Rose F, et al. Combination therapy with oral sildenafil and inhaled iloprost for severe pulmonary hypertension. Ann Intern Med 2002; 136: 515-522.

29 Galiè N, Ghofrani HA, Torbicki A, et al. Sildenafil Use in Pulmonary Arterial Hypertension (SUPER) study group. Sildenafil citrate therapy for pulmonary arterial hypertension. N Engl J Med 2005; 353: 2148-2157.

30 Galiè N, Brundage BH, Ghofrani HA, et al. Tadalafil therapy for pulmonary arterial hypertension. Circulation 2009; 119: 2894-2903.

31 Bhatia S, Frantz RP, Severson CJ, et al. Immediate and long-term hemodynamic and clinical effects of sildenafil in patients with pulmonary arterial hypertension receiving vasodilator therapy. Mayo Clin Proc 2003; 78: 1207-1213.

32 Grimminger F, Weimann G, Frey R, et al. First acute haemodynamic study of soluble guanylate cyclase stimulator riociguat in pulmonary hypertension. Eur Respir J 2009; 33: 785-792.

33 Ghofrani HA, Hoeper MM, Halank M, et al. Riociguat for chronic thromboembolic pulmonary hypertension and pulmonary arterial hypertension: a phase II study. Eur Respir J 2010; 36: 792-799.

34 Mubarak KK. A review of prostaglandin analogs in the management of patients with pulmonary arterial hypertension. Respir Med 2010; 104: 9-21.

35 Christman BW, McPherson CD, Newman JH, et al. An imbalance between the excretion of thromboxane and prostacyclin metabolites in pulmonary hypertension. N Engl J Med 1992; 327: 70-75.

36 Tuder RM, Cool CD, Geraci MW, et al. Prostacyclin synthase expression is decreased in lungs from patients with severe pulmonary hypertension. Am J Respir Crit Care Med 1999; 159: 1925-1932.

37 Abramovitz M, Adam M, Boie Y, et al. The utilization of recombinant prostanoid receptors to determine the affinities and selectivities of prostaglandins and related analogs. Biochim Biophys Acta 2000; 1483: 285-293.

38 Kuwano K, Hashino A, Asaki T, et al. 2-[4-[(5,6-diphenylpyrazin-2yl)(isopropyl)amino]butoxy]-N-(methylsulfonyl)acetamide (NS-304), an orally available and long-acting prostacyclin receptor agonist prodrug. J Pharmacol Exp Ther 2007; 322: 1181-1188.

39 Farber HW, Miller DP, Beery FS, et al. Use of parenteral prostanoids at time of death in patients with pulmonary arterial hypertension in REVEAL. Chest 2011; 140: 903A.

40 Rubin LJ, Parikh K, Pulido T, et al. FREEDOM-M: efficacy and safety of oral treprostinil diethanolamine as monotherapy in patients with pulmonary arterial hypertension. Chest 2011; 140: 1044A.

41 United Therapeutics. FREEDOM-C trial of oral treprostinil in pulmonary arterial hypertension fails to meet primary endpoint. 
November 17, 2008. http://ir.unither.com/releasedetail.cfm? ReleaseID=347887 Date last accessed: August 1, 2012.

42 United Therapeutics. FREEDOM-M trial of oral treprostinil in pulmonary arterial hypertension meets primary endpoint. June 6 , 2011. http://ir.unither.com/releasedetail.cfm?ReleaseID $=582786$ Date last accessed: August 1, 2012.

43 Melian EB, Goa KL. Beraprost: a review of its pharmacology and therapeutic efficacy in the treatment of peripheral arterial disease and pulmonary arterial hypertension. Drugs 2002; 62: 107-133.

44 Rich J, Hoeper MM. The search for an oral prostanoid to treat pulmonary arterial hypertension continues. Are we getting any closer? Int J Clin Pract Suppl 2009; 161: 17-18.

45 Ikeda D, Tsujino I, Sakaue S, et al. Pilot study of short-term effects of a novel long-acting oral beraprost in patients with pulmonary arterial hypertension. Circ J 2007; 71: 1829-1831.

46 Oudiz RJ, Benza RL, Delcroix M, et al. Long-term follow-up in PAH patients dosed with beraprost sodium modified release (BPSMR) tablets, an oral twice daily prostacyclin analogue. Am J Respir Crit Care Med 2011; 183: A5905.

47 Armstrong DJ, Benza RL, Delcroix M, et al. Clinical pharmacology and safety of beraprost sodium modified release (BPS-MR), an oral twice daily prostacyclin analogue - a phase II study. Am J Respir Crit Care Med 2010; 181: A3360.

48 Morrison K, Ernst R, Hess P, et al. Selexipag: a selective prostacyclin receptor agonist that does not affect rat gastric function. J Pharmacol Exp Ther 2010; 335: 249-255.

49 Simonneau G, Torbicki A, Hoeper MM, et al. Selexipag, an oral, selective IP receptor agonist for the treatment of pulmonary arterial hypertension. Eur Respir J 2012; 40: 874-880.

50 Freyhaus H, Dumitrescu D, Berghausen E, et al. Imatinib mesylate for the treatment of pulmonary arterial hypertension. Expert Opin Investig Drugs 2012; 21: 119-134.
51 Barst RJ. PDGF signaling in pulmonary arterial hypertension. J Clin Invest 2005; 115: 2691-2694.

52 Schermuly RT, Dony E, Ghofrani HA, et al. Reversal of experimental pulmonary hypertension by PDGF inhibition. J Clin Invest 2005; 115: 2811-2821.

53 Redner RL. Why doesn't imatinib cure chronic myeloid leukemia? Oncologist 2010; 15: 182-186.

54 Ghofrani HA, Seeger W, Grimminger F. Imatinib for the treatment of pulmonary arterial hypertension. N Engl J Med 2005; 353: 1412-1413.

55 Patterson KC, Weissmann A, Ahmadi T, et al. Imatinib mesylate in the treatment of refractory idiopathic pulmonary arterial hypertension. Ann Intern Med 2006; 145: 152-153.

56 Souza R, Sitbon O, Parent F, et al. Long term imatinib treatment in pulmonary arterial hypertension. Thorax 2006; 61: 736.

57 Ghofrani HA, Morrell NW, Hoeper MM, et al. Imatinib in pulmonary arterial hypertension patients with inadequate response to established therapy. Am J Respir Crit Care Med 2010; 182: 1171-1177.

58 Hoeper MM, Barst R, Bourge R, et al. Imatinib improves exercise capacity and hemodynamics at 24 weeks as add-on therapy in symptomatic pulmonary arterial hypertension patients: the IMPRES Study. Chest 2011; 140: 1045A.

59 Montani D, Bergot E, Günther S, et al. Pulmonary arterial hypertension in patients treated by dasatinib. Circulation 2012; 125: 2128-2137.

60 Ghofrani HA, Al-Hiti H, Vonk-Noordegraaf A, et al. Proof-ofconcept study to investigate the efficacy, hemodynamics and tolerability of terguride vs. placebo in subjects with pulmonary arterial hypertension: results of a double blind, randomised, prospective phase IIa study. Am J Respir Crit Care Med 2012; 185: A2496. 